\title{
Atmospheric new particle formation: real and apparent growth of neutral and charged particles
}

\author{
J. Leppä ${ }^{1}$, T. Anttila ${ }^{1}$, V.-M. Kerminen ${ }^{1}$, M. Kulmala ${ }^{2}$, and K. E. J. Lehtinen ${ }^{3}$ \\ ${ }^{1}$ Finnish Meteorological Institute, P.O. Box 503, 00101 Helsinki, Finland \\ ${ }^{2}$ Department of Physics, P.O. Box 64, 00014, University of Helsinki, Finland \\ ${ }^{3}$ Finnish Meteorological Institute, Kuopio Unit, and University of Eastern Finland, Department of Physics and Mathematics, \\ P.O. Box 1627, 70211 Kuopio, Finland
}

Received: 11 November 2010 - Published in Atmos. Chem. Phys. Discuss.: 20 January 2011

Revised: 12 April 2011 - Accepted: 3 May 2011 - Published: 27 May 2011

\begin{abstract}
In this study we have provided simple analytical formulae to estimate the growth rate of a nucleation mode due to self-coagulation and the apparent growth rate due to coagulation scavenging by larger particles. These formulae were used on a set of simulations covering a wide range of atmospheric conditions. The modal growth rates were determined from the simulation results by summing the contribution of each process, by calculating the increase rate in the count mean diameter of the mode and by following the peak concentration of the mode. The results of these three methods were compared with each other and the means used to estimate the growth rate due to self-coagulation and coagulation scavenging were found to give accurate values. We also investigated the role of charged particles and electric interactions in the growth of a nucleation mode. Charged particles were found to increase the growth rate due to both self-coagulation and coagulation scavenging by a factor of $\sim 1.5$ to 2 . In case of increased condensation onto charged particles, the total condensational growth rate of a nucleation mode may increase significantly in the very early steps of the growth. The analytical formulae provided by this paper were designed to provide the growth rates due to different processes from aerosol dynamic simulations, but the same principles can be used to determine the growth rates from measurement data.
\end{abstract}

\section{Introduction}

Atmospheric nucleation is the dominant source of aerosol particles in the global atmosphere (Spracklen et al., 2006; Kulmala and Kerminen, 2008; Yu et al., 2010), and a sig-

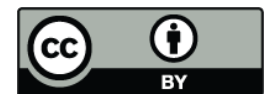

Correspondence to: J. Leppä

(johannes.leppa@fmi.fi) nificant contributor to particles capable of acting as cloud condensation nuclei (Spracklen et al., 2008; Merikanto et al., 2009; Pierce and Adams, 2009). The efficacy by which nucleated particles reach climatically-relevant sizes depends essentially on two competing factors: the nuclei growth rate and the scavenging of nuclei by various removal processes (Kerminen et al., 2001; Lehtinen et al., 2007; Pierce and Adams, 2007; Kuang et al., 2009; Gong et al., 2010). Of specific interest in this regard is the growth rate of sub- $20 \mathrm{~nm}$ diameter nuclei, since they are most susceptible for coagulation scavenging by larger pre-existing particles.

After being formed at about 1.5 to $2 \mathrm{~nm}$ (Kulmala et al., 2007), nucleated particles grow in size by condensation of low-volatile vapors, nuclei self-coagulation, and possibly by heterogeneous reactions (e.g., Stolzenburg et al., 2005). Condensation of polar vapors, such as sulfuric acid, is enhanced by the presence of charges in the growing nuclei (Laakso et al., 2003; Nadykto and Yu, 2003; Lushnikov and Kulmala, 2004). Charges also influence nuclei coagulation rates, the effect of which is most pronounced for nuclei of opposite charge (e.g., Hoppel and Frick, 1986; Hõrrak et al., 2008). In addition to the real growth, an atmospheric population of nuclei may also experience apparent growth due to the preferential removal of the smallest nuclei (Stolzenburg et al., 2005). The main removal mechanism in this regard is coagulation scavenging, dry deposition being usually of minor importance (Kerminen et al., 2004). From modeling point of view, nuclei self-coagulation and coagulation scavenging can be treated quite accurately, whereas condensation and heterogeneous processes are problematic because of our incomplete knowledge of the vapors participating into these processes and the general lack of knowledge of vapor properties (e.g., Nieminen et al., 2010; Wang et al., 2010).

Several methods have been developed for determining nuclei growth rates from atmospheric observations. All of them rely on particle number size distribution measurements of

Published by Copernicus Publications on behalf of the European Geosciences Union. 
either total or of charged particles. The simplest available methods follow the time evolution of a distinct nucleation mode as it grows to larger sizes (e.g., Dal Maso et al., 2005; Hirsikko et al., 2005). These methods provide very limited amount of information on how the growth rate varies with nuclei size, and practically no information on the contribution of individual processes to the observed growth. Roughly the same is true for the method by Iida et al. (2008) designed for more complex nuclei growth situations. Process-level information on the nuclei growth can be obtained using inverse modeling procedures based on solving the aerosol general dynamic equation (Verheggen and Mozurkewich, 2006). Such approaches work best for laboratory measurements and, to our knowledge, have not yet been applied to atmospheric measurements.

The main goal of this paper is to improve our ability to model and analyze nuclei growth rates in the atmosphere. The coagulation of particles can easily be simulated by detailed aerosol dynamical models, but retrieving the growth rate caused by the coagulation is not so straightforward. The particle growth rates observed in the measurements have been used to estimate the concentrations of condensable vapors often assuming that the growth is purely due to condensation (see e.g., Kulmala et al., 2001; Kristensson et al., 2008). Our aim is to provide simple methods to estimate the growth rate due to coagulation processes for the analysis of both simulated and measured data. Another possibly important, but very complicated, issue is the effect of particle charges on the particle growth rate. This topic is also covered in this study with the emphasis on the effect of charges on growth due to coagulation processes.

To start with, we will introduce a few very simple analytical formulae by which the role of individual growth processes can be estimated from either model or measurement data. The performance of these formulae will be tested with a comprehensive set of model simulations, which requires addressing a few numerical issues. The paper will be completed by a thorough analysis of the nuclei growth behavior due to condensation, self-coagulation and coagulation scavenging in the presence of charges in aerosol particles. Heterogeneous reactions will not be considered here, since the mechanistic understanding of that process is still far from complete. We aim to address the following specific questions: (1) How accurately can we estimate the nuclei growth rates due to individual processes by using simple analytical formulae, such as the ones derived here?, (2) What are the main numerical problems in simulating nuclei growth with a sectional model, and how can these problems be dealt with?, (3) What is the relative importance of the considered real and apparent growth processes in different atmospheric situations and for different nuclei sizes? and (4) How is nuclei growth affected by the presence of charges?

\section{Tools and methods}

In this work, we describe simple methods that can be used to estimate the growth rate of a nucleation mode from simulation data obtained using a sectional model. The processes participating in the growth are condensation, selfcoagulation and coagulation scavenging. Additionally, we investigate the importance of charged particles in the growth of a nucleation mode.

\subsection{Theory}

\subsubsection{Definition of growth}

We assume that aerosol particles are spherical and thus have a well-defined diameter. By growth of a single particle we mean the increase of the diameter of that particle. The particle diameter increases due to condensation of vapor molecules onto the particle surface, which is the only process participating in the growth of a single particle in our approach.

For the growth of a particle population, we need to define the population and to specify the diameter that we use to describe the population. The growth of the population is then the increase in that diameter. In this study, we use two different definitions of a diameter describing the nucleation mode: the diameter of the peak of the particle number size distribution and the count mean diameter of particles smaller than $45 \mathrm{~nm}$ in diameter. In a sectional model, the count mean diameter $\left(d_{\mathrm{p}}^{*}\right)$ can be calculated using the following equation:

$d_{\mathrm{p}}^{*}=\frac{\sum_{i=1}^{n} N_{i} d_{\mathrm{p}, i}}{\sum_{i=1}^{n} N_{i}}$

where $d_{p, i}$ and $N_{i}$ are the diameter and number concentration of particles in section $i$, and the section $n$ is the last section with diameter $\leq 45 \mathrm{~nm}$.

A particle population grows in size through the condensational growth of each particle in the population. The condensational growth rate, $\mathrm{GR}_{\text {cond }}$, may not be the same for all particles in the mode, but a single value can be assigned for the population as an increase rate of the diameter describing that population. A population also grows due to selfcoagulation (i.e. coagulation of particles in the population with each other) and coagulation scavenging (i.e. coagulation of particles in the population with pre-existing bigger particles). Self-coagulation decreases the particle number concentration in the mode, but increases the average diameter of the particles, which results in the growth of the diameter describing the population. Coagulation scavenging decreases the number concentration of particles in that population, and the small particles are removed more rapidly than the big particles. Thus the diameter describing the population increases, but the growth is only apparent, as none of the particles in the mode get any bigger. 
One problem in defining the growth rate of the growing mode due to scavenging of particles by larger particles, $\mathrm{GR}_{\text {scav }}$, is the separation of these two groups of particles. In our approach, we have chosen to estimate the value of $\mathrm{GR}_{\text {scav }}$ by calculating the increase rate in the count mean diameter of particles smaller than $45 \mathrm{~nm}$ due to scavenging by particles larger than $45 \mathrm{~nm}$ in diameter.

\subsubsection{Condensation}

Under most atmospheric conditions, aerosol particles grow mainly due to condensation of vapors onto particle surfaces. In the kinetic regime, the molecular flux onto a particle of diameter $d_{\mathrm{p}}$ is (e.g., Seinfeld and Pandis, 2006)

$J=\frac{\pi}{4} d_{\mathrm{p}}^{2} v \alpha\left(c_{\infty}-c_{\mathrm{s}}\right)$

where $v$ is the mean speed of the molecules, $c_{\infty}$ and $c_{s}$ are the number concentration of condensing molecules far away from the particle and the saturation vapor concentration at the particle surface, respectively, and $\alpha$ is the molecular accommodation coefficient. The time derivative of the particle volume is then $d V_{p} / d t=J V_{m}$, where $V_{m}$ is the volume of the condensing vapor molecule. The growth rate of a particle diameter due to condensation is then

$\mathrm{GR}_{\mathrm{cond}}=\frac{1}{2} V_{m} \nu \alpha\left(c_{\infty}-c_{s}\right)$.

In these conditions the growth rate depends on the particle diameter only through the Kelvin effect, which affects the value of $c_{s}$. For a non-volatile vapor, $c_{s}$ is negligible and the growth rate is constant as a function of diameter.

The condensational growth of bigger particles is typically modeled using a continuum regime expression with a transition regime correction factor (Fuchs and Sutugin, 1971). This approach results in a condensational growth rate that is different to the constant value of growth rate in the kinetic regime. The condensational growth rate of particles $\sim 100 \mathrm{~nm}$ in diameter deviate $17 \%$ from the constant value and the deviation increases as a function of diameter. Thus the assumption of a constant growth rate is quite good for particles $<100 \mathrm{~nm}$ in diameter. Furthermore, taking into account the molecular-like properties of the very smallest particles introduces diameter dependence into the growth rate for particles $<10 \mathrm{~nm}$ in diameter (Lehtinen and Kulmala 2003; Nieminen et al., 2010). In this case, the corrected growth rate of $4.5 \mathrm{~nm}$ sized particles deviates by $20 \%$ from the constant value. The growth rates analyzed from the ambient measurements typically show an increase in the condensational growth rate as a function of particle diameter (e.g., Manninen et al., 2010). Even though the assumption of constant growth rate applies only to condensation of non-volatile vapors to particles in certain size range, we will keep the condensational growth rate of neutral particles constant as a function of diameter in this study. This affects the dynamics of the particles in the simulations, but simplifies the analysis of the simulation results. The conclusions made in this paper are not affected by this choice.

Condensation of polar molecules may lead to increased condensational flux onto charged particles. We take this into account by multiplying the molar flux onto a particle surface with the following factor (Lushnikov and Kulmala, 2004):

$\xi\left(d_{\mathrm{p}}\right)=1+\frac{1}{4 \pi \varepsilon_{0}} \frac{4 \gamma e^{2} r}{d_{\mathrm{p}}^{2}}$

Here $e$ is the elementary charge $\left(1.60 \times 10^{-19} \mathrm{C}\right), d_{\mathrm{p}}$ is the particle diameter in meters, $\varepsilon_{0}$ is the vacuum permittivity $\left(8.85 \times 10^{-12} \mathrm{Fm}^{-1}\right)$ and $\gamma=1 / k T$, where $T$ is the temperature in Kelvins and $k$ is the Boltzmann constant $\left(1.38 \times 10^{-23} \mathrm{~J} \mathrm{~K}^{-1}\right)$. A polar molecule can formally be described as a compound having a negative and positive charge set a part by a fixed distance. This distance, given in meters, is denoted by $r$ in Eq. (4) and a value corresponding to sulfuric acid molecule was used in this study.

\subsubsection{Self-coagulation}

To estimate the growth rate due to self-coagulation analytically, we make a simplifying assumption that the particle number size distribution of a growing population can be described by a monodisperse distribution. This distribution has four parameters: the number concentrations of neutral, negative and positive particles $\left(N_{0}, N_{-}, N_{+}\right)$and the diameter of the particles $\left(d_{\mathrm{p}}\right)$. Here we assume that $N_{0}, N_{-}$and $N_{+}$are equal to the total number concentration of neutral, negative and positive particles in the population and $d_{\mathrm{p}}$ is the count mean diameter of the population. The total volume concentration can be expressed as

$V_{\mathrm{tot}}=N V_{\mathrm{p}}=N \frac{\pi d_{\mathrm{p}}^{3}}{6}$

where $V_{\mathrm{p}}$ and $V_{\text {tot }}$ are the volume of a single particle and the total volume concentration of particles in the mode, respectively. Assuming that $V_{\text {tot }}$ stays constant, we can calculate the growth rate due to self-coagulation:

$\mathrm{GR}_{\text {scoag }}=\frac{d d_{\mathrm{p}}}{d t}=-\frac{d_{\mathrm{p}}}{3 N} \frac{d N}{d t}$.

For a monodisperse distribution with three charge classes, the time derivative of the total number concentration due to self-coagulation is the following:

$$
\begin{aligned}
\frac{d N}{d t}= & -\frac{1}{2}\left(k_{00}\left(d_{\mathrm{p}}\right) N_{0}^{2}+k_{--}\left(d_{\mathrm{p}}\right) N_{-}^{2}+k_{++}\left(d_{\mathrm{p}}\right) N_{+}^{2}\right) \\
& -k_{0-}\left(d_{\mathrm{p}}\right) N_{0} N_{-}-k_{0+}\left(d_{\mathrm{p}}\right) N_{0} N_{+}-k_{-+}\left(d_{\mathrm{p}}\right) N_{-} N_{+} .
\end{aligned}
$$

Here $k_{00}, k_{--}$and $k_{++}$are the self-coagulation coefficients of neutral, negative and positive particles, respectively, $k_{0-}$ 
and $k_{0+}$ are the coagulation coefficients of negative and positive particles to neutral particles, $k_{-+}$is the coagulation coefficient of negative and positive particles and $N$ is the total number concentration of particles. Using Eqs. (6) and (7), we get the following equation for the growth rate due to selfcoagulation:

$$
\begin{aligned}
\operatorname{GR}_{\text {scoag }}\left(d_{\mathrm{p}}\right)= & \frac{d_{\mathrm{p}}}{3 N}\left[\frac{1}{2}\left(k_{00}\left(d_{\mathrm{p}}\right) N_{0}^{2}+k_{--}\left(d_{\mathrm{p}}\right) N_{-}^{2}+k_{++}\left(d_{\mathrm{p}}\right) N_{+}^{2}\right)\right. \\
& \left.+k_{0-}\left(d_{\mathrm{p}}\right) N_{0} N_{-}+k_{0+}\left(d_{\mathrm{p}}\right) N_{0} N_{+}+k_{-+}\left(d_{\mathrm{p}}\right) N_{-} N_{+}\right](8)
\end{aligned}
$$

Assuming that all the particles in the mode are neutral, Eq. (8) simplifies to

$\operatorname{GR}_{\text {scoag }}\left(d_{\mathrm{p}}\right)=\frac{d_{\mathrm{p}}}{6} k_{00}\left(d_{\mathrm{p}}\right) N$,

where $N$ is the total number concentration of particles in the mode.

Eqs. (8) and (9) are exact only for a monodisperse distribution. However, they can be used to estimate the growth rate due to self-coagulation even if the growing mode consists of particles with varying sizes, but the accuracy of the equations decrease as the width of the mode increases. In Section 3.2 we will show that Eqs. (8) and (9) can be used to determine the growth rate due to self-coagulation of a nucleation mode in atmospherically relevant conditions.

\subsubsection{Coagulation scavenging}

In the atmosphere, nucleation mode particles are scavenged by coagulation with pre-existing larger particles, which will be denoted as a background in this study. The coagulation with the background decreases the particle number concentration in the nucleation mode by a diameter dependent rate, with small particles coagulating more rapidly than bigger ones. This results in the apparent growth of the nucleation mode as the count mean diameter of the mode increases. The phenomenon was studied for a growing lognormal mode by Stolzenburg et al. (2005). Here we develop a theory that applies for distributions of any shape.

Using a discrete representation of the particle number size distribution, the value of coagulation sink for the particles in a section $i$ is

$\operatorname{CoagS}_{i}=\sum_{j=p}^{q} k_{i, j} N_{j}$,

where $k_{i, j}$ is the coagulation coefficient between the particles in sections $i$ and $j$ and the background particles are in the sections from $p$ to $q$. If other processes are neglected, the time derivative of the concentration of particles in section $i$ is

$\frac{d N_{i}}{d t}=-\operatorname{CoagS}_{i} N_{i}$

If we describe the size of the mode by using the count mean diameter $\left(d_{\mathrm{p}}^{*}\right)$ of the mode (Eq. 1), the growth rate due to coagulation scavenging can be defined as a time derivative of that diameter:

$\mathrm{GR}_{\mathrm{scav}}=\frac{d d_{\mathrm{p}}^{*}}{d t}=\frac{d}{d t}\left(\frac{\sum_{i=1}^{n} N_{i} d_{\mathrm{p}, i}}{\sum_{i=1}^{n} N_{i}}\right)$.

After performing the derivation in Eq. (12) and using Eq. (11), the $\mathrm{GR}_{\text {scav }}$ simplifies to

$$
\begin{aligned}
\mathrm{GR}_{\text {scav }} & =d_{\mathrm{p}}^{*} \frac{\sum_{i=1}^{n} \operatorname{CoagS}_{i} N_{i}}{\sum_{i=1}^{n} N_{i}}-\frac{\sum_{i=1}^{n} \operatorname{CoagS}_{i} N_{i} d_{\mathrm{p}, i}}{\sum_{i=1}^{n} N_{i}} \\
& =d_{\mathrm{p}}^{*} \times \text { CoagS }^{*}-\left(d_{\mathrm{p}} \times \text { CoagS }\right)^{*},
\end{aligned}
$$

where star denotes the count mean value over the nucleation mode.

In Eq. (13), all the particles are assumed to be neutral. The coagulation coefficients are substantially different if one or both of the particles are charged, so we need to extend Eq. (13) to consider also particle charges. In this case, the count mean diameter of the nucleation mode is

$d_{\mathrm{p}}^{\dagger}=\frac{\sum_{i=1}^{n}\left(N_{i}^{0}+N_{i}^{-}+N_{i}^{+}\right) d_{\mathrm{p}, i}}{\sum_{i=1}^{n}\left(N_{i}^{0}+N_{i}^{-}+N_{i}^{+}\right)}$,

where $N_{i}^{0}, N_{i}^{-}$and $N_{i}^{+}$are the number concentrations of neutral, negative and positive particles in the section $i$, respectively. The background particles scavenging the nucleation mode particles also have different charges, which should be taken into account when calculating the coagulation sinks of the nucleation mode particles:

$$
\begin{aligned}
\operatorname{CoagS}_{i}^{0} & =\sum_{j=p}^{q}\left(k_{i, j}^{0,0} N_{j}^{0}+k_{i, j}^{0,-} N_{j}^{-}+k_{i, j}^{0,+} N_{j}^{+}\right) \\
\operatorname{CoagS}_{i}^{-} & =\sum_{j=p}^{q}\left(k_{i, j}^{-, 0} N_{j}^{0}+k_{i, j}^{-,-} N_{j}^{-}+k_{i, j}^{-,+} N_{j}^{+}\right) \\
\operatorname{CoagS}_{i}^{+} & =\sum_{j=p}^{q}\left(k_{i, j}^{+, 0} N_{j}^{0}+k_{i, j}^{+,-} N_{j}^{-}+k_{i, j}^{+,+} N_{j}^{+}\right),
\end{aligned}
$$

where $k_{i, j}^{a, b}$ is the coagulation coefficient between particles in sections $i$ and $j$, with $a$ and $b$ denoting the charge classes of those particles. The growth rate due to coagulation scavenging can again be calculated as the time derivative of the count mean diameter $\left(d_{\mathrm{p}}^{\dagger}\right)$ :

$$
\begin{aligned}
\mathrm{GR}_{\mathrm{scav}}= & d_{\mathrm{p}}^{\dagger} \frac{\sum_{i=1}^{n}\left(\operatorname{CoagS}_{i}^{0} N_{i}^{0}+\operatorname{CoagS}_{i}^{-} N_{i}^{-}+\operatorname{CoagS}_{i}^{+} N_{i}^{+}\right)}{\sum_{i=1}^{n}\left(N_{i}^{0}+N_{i}^{-}+N_{i}^{+}\right)} \\
& -\frac{\sum_{i=1}^{n}\left(\operatorname{CoagS}_{i}^{0} N_{i}^{0}+\operatorname{CoagS}_{i}^{-} N_{i}^{-}+\operatorname{CoagS}_{i}^{+} N_{i}^{+}\right) d_{\mathrm{p}, i}}{\sum_{i=1}^{n}\left(N_{i}^{0}+N_{i}^{-}+N_{i}^{+}\right)}
\end{aligned}
$$

or simply

$\mathrm{GR}_{\text {scav }}=d_{\mathrm{p}}^{\dagger} \times \mathrm{Coag}^{\dagger}-\left(d_{\mathrm{p}} \times \mathrm{CoagS}\right)^{\dagger}$,

where dagger denotes the count mean value over the nucleation mode with three charge classes. 


\subsection{Model}

We have used the aerosol dynamical box model IonUHMA (University of Helsinki Multicomponent Aerosol model for neutral and charged particles) which simulates the dynamical processes governing the time evolution of the aerosol particle size distribution (Leppä et al., 2009). In the model, particles are divided into a user-specified number of size sections and three charge classes, namely neutral, negatively charged and positively charged particles. The model solves the number concentration of particles in each size section and each charge class. Besides particles, the model includes pools of charged clusters or molecules that are smaller than $1.5 \mathrm{~nm}$ in diameter. The actual nucleation process is not simulated in Ion-UHMA, but the formation rate of new particles is used as an input parameter in the model. This approach incorporates an assumption that the new particle formation and growth are independent of each other, which is quite plausible based on our current understanding on atmospheric nucleation (Kulmala et al., 2000, 2004). Here, particles are assumed to be formed at $1.5 \mathrm{~nm}$, which is reasonable based on available atmospheric measurements (Kulmala et al., 2007; Manninen et al., 2010). The concentrations of particles and charged sub $1.5 \mathrm{~nm}$ clusters are tracked separately. The processes used in this study were condensation, coagulation and ion-aerosol attachment.

In Ion-UHMA, the diameters corresponding to size sections are fixed and the size sections are divided equally on a logarithmic scale. As the particles in section $n$ grow due to condensation during one time step $(\Delta t)$, their diameter increases to a value between the diameters corresponding to sections $n$ and $n+1\left(d_{\mathrm{p}, n}<d_{\mathrm{p}, x}<d_{\mathrm{p}, n+1}\right)$. Those particles are then divided to sections $n$ and $n+1$ in such a way that the number and volume concentrations of particles are conserved (see, e.g., Jacobson 2005):

$$
\begin{gathered}
N_{n}=\frac{d_{\mathrm{p}, n+1}^{3}-d_{\mathrm{p}, x}^{3}}{d_{\mathrm{p}, n+1}^{3}-d_{\mathrm{p}, n}^{3}} N_{x} \\
N_{n+1}=\frac{d_{\mathrm{p}, x}^{3}-d_{\mathrm{p}, n}^{3}}{d_{\mathrm{p}, n+1}^{3}-d_{\mathrm{p}, n}^{3}} N_{x}
\end{gathered}
$$

Here, $N_{x}$ is the number concentration of particles with diameter $d_{\mathrm{p}, x}$. This leads to underestimation of count mean diameter of the particle population and, furthermore, effectively lower growth rate due to condensation. The count mean diameter after the particles are divided into the two sections is

$d_{\mathrm{p}}^{+}=\frac{d_{\mathrm{p}, n} N_{n}+d_{\mathrm{p}, n+1} N_{n+1}}{N_{n}+N_{n+1}}$.

The condensational growth rate is $\mathrm{GR}_{\text {cond }}=\left(d_{\mathrm{p}, x}-d_{\mathrm{p}, n}\right) / \Delta t$, but the effective growth rate of the count mean diameter is $\mathrm{GR}_{\mathrm{eff}}=\left(d_{\mathrm{p}}^{\ddagger}-d_{\mathrm{p}, n}\right) / \Delta t$. Using these definitions and Eqs. (20),
(21) and (22), we get the following relation between $\mathrm{GR}_{\text {cond }}$ and $\mathrm{GR}_{\mathrm{eff}}$ :

$\mathrm{GR}_{\mathrm{eff}}=\frac{3 d_{\mathrm{p}, n}^{2}+3 d_{\mathrm{p}, n} \Delta d_{\mathrm{p}, n}+\Delta d_{\mathrm{p}, n}^{2}}{d_{\mathrm{p}, n}^{2}\left(1+f+f^{2}\right)} \mathrm{GR}_{\mathrm{cond}}$,

where $\Delta d_{\mathrm{p}, n}$ is the increase in diameter of the particles in section $n$ due to condensation during one time step and $f$ is $d_{\mathrm{p}, n+1} / d_{\mathrm{p}, n}$. By assuming $\Delta d_{\mathrm{p}, n} \ll d_{\mathrm{p}, n}, \mathrm{GR}_{\mathrm{eff}}$ can be approximated as

$\mathrm{GR}_{\mathrm{eff}}=\frac{3}{1+f+f^{2}} \mathrm{GR}_{\text {cond }}$.

The ratio between the diameters corresponding to consecutive sections, $f$, approaches unity with increasing number of size sections, and thus the $\mathrm{GR}_{\text {eff }}$ approaches $\mathrm{GR}_{\text {cond. }}$. It should be noted that Eq. (24) can only be used to estimate the effective condensational growth rate in a sectional model with fixed sections divided evenly on a logarithmic scale.

If the condensational flux onto charged particles is increased according to Eq. (4), the condensational growth rate of charged particles is increased and thus the condensational growth rate of the total population is increased. In this case, the effective growth rate of the total population can be estimated

$\mathrm{GR}_{\text {eff, charged }}=\frac{3}{1+f+f^{2}} \frac{N_{n}^{0}+\xi\left(d_{\mathrm{p}, n}\right)\left(N_{n}^{-}+N_{n}^{+}\right)}{N_{n}} \mathrm{GR}_{\text {cond }}$,

where $n$ denotes the section with maximum concentration.

In Ion-UHMA, the coagulation coefficients are calculated using the flux matching theory according to Fuchs (1964), and when one or both of the particles are charged, the coefficients are corrected according to Howard et al. (1973) and Mick et al. (1991). The particles produced by coagulation are divided into the two sections with corresponding diameters closest to the diameter of the produced particles according to Eqs. (20) and (21) (Lehtinen and Zachariah, 2001). The charge is conserved in coagulation, except when two singlycharged negative or positive particles collide, in which case the resulting particle is still singly-charged as there are only three charge classes in the model (neutral, negative and positive).

The attachment coefficients of charged clusters and particles in Ion-UHMA are calculated using the parameterized version (Hõrrak et al., 2008) of the theory presented by Hoppel and Frick (1986). The ion-aerosol attachment has negligible effect on the particle sizes, but in most of the cases it is the major factor driving the particle population towards the charge equilibrium (Kerminen et al., 2007). Depending on the input values, i.e. the nucleation mechanism, some of the freshly formed particles may be charged. As the newly formed particles start to grow to bigger sizes, they are also subject to the attachment of clusters, which charges the neutral particles and neutralizes the charged ones. Eventually, the particle population approaches the charge equilibrium. 


\subsection{Simulation setup and parameters}

This study consists of three different sets of simulations (Set 1, Set 2 and Set 3). In each simulation, the simulated particle diameter range was from 1.5 to $1000 \mathrm{~nm}$. The number of size sections used was 80 in Sets 2 and 3, but it was varied in Set 1 . The formation of new particles was modeled by assuming a nucleation rate that follows a sinusoidal pattern as a function of time. The new particle formation was assumed to start at the beginning of the simulation and the duration of new particle formation was varied. The mean nucleation rate over the period of particle formation was used as an input parameter in the model. The growth rate of neutral particles due to condensation was used as input as well, and it was kept constant as a function of time and particle diameter. The pre-existing particle population was modeled by a single log-normal mode with a peak diameter of $150 \mathrm{~nm}$ and standard deviation of 1.5. The concentration of particles in the pre-existing mode was varied in the model.

\subsubsection{Set 1 - numerical diffusion and error due to sectional approach}

Set 1 simulations were conducted in order to test how much the numerical diffusion affects the condensational growth of a particle mode and how well we can estimate the error in the increase of count mean diameter by using Eq. (24). In this set, only new particle formation and condensation was modeled, the concentration of particles in the pre-existing mode was set to zero, and all particles were assumed to be neutral. In Set 1, the following parameters were varied: the duration of new particle formation, condensational growth rate and number of size sections. The values of the parameters are presented in Table 1 and all the combinations of the input parameters were used in the simulations. The different combinations of the duration of new particle formation and the value of $\mathrm{GR}_{\text {cond }}$ were used to produce nucleation modes with varying widths. The width of the mode may affect the modal growth rate through numerical diffusion.

\subsubsection{Set 2 - self-coagulation and coagulation scavenging}

Set 2 simulations were conducted in order to test how well we can estimate the growth rate due to self-coagulation using Eqs. (8) and (9) and the apparent growth rate of the nucleation mode caused by the scavenging by larger particles using Eqs. (19) and (13). In Set 2,the following parameters were varied: the condensational growth rate of neutral particles, new particle formation rate, duration of new particle formation, concentration of particles in the pre-existing particle population and whether the charged particles and electric interactions were included or not. The values of the parameters are presented in Table 2, and all combinations of the parameters were used in the simulations.
Table 1. The values of varied parameters used as input in the model in Set 1.

\begin{tabular}{ll}
\hline Parameter & $\begin{array}{l}\text { Values used as input } \\
\text { in the model }\end{array}$ \\
\hline Number of size sections & $50 / 80 / 120 / 200$ \\
Duration of new particle formation & $1 / 3 / 6 \mathrm{~h}$ \\
Condensational growth rate of neutral particles & $1 / 3 / 10 \mathrm{~nm} \mathrm{~h}^{-1}$ \\
\hline
\end{tabular}

The parameters used in Set 2 were chosen to represent new particle formation events with wide ranges of mode widths and particle concentrations. The concentrations of background particles were chosen to yield condensation sink values from $7.3 \times 10^{-4}$ to $1.5 \times 10^{-2} \mathrm{~s}^{-1}$, which covers most of the observed values of condensation sink during new particle formation events in continental background areas (Birmili et al., 2003; Held et al., 2004; Dal Maso et al., 2007). Higher values of background particle concentrations were excluded, since only high values of new particle formation rates would yield observable events under such conditions. It should be noted that these are the values of condensation sink in the beginning of the simulation, but the value increases as the background particles grow due to condensation. All of the parameter values are atmospherically relevant, but some of the parameter combinations may not be realistic.

All the simulations were conducted both purely neutral and with charged particles and electric interactions included. In the simulations with charged particles, $10 \%$ of the particles were formed charged with equal amount of both polarities. The concentrations of charged sub $1.5 \mathrm{~nm}$ clusters were kept constant at $1000 \mathrm{~cm}^{-3}$ for both polarities, and the attachment of these clusters into aerosol particles was simulated. The chosen fraction of particles formed charged and the concentrations of charged clusters are in line with the measurements conducted at a field station in a boreal forest (e.g., Laakso et al., 2007; Gagné et al., 2008; Manninen et al., 2010). The particle charges were taken into account in the coagulation coefficients, but the value of $\mathrm{GR}_{\text {cond }}$ was assumed to be the same for the neutral and the charged particles.

\subsubsection{Set 3 - charges}

Set 3 simulations were conducted in order to investigate the range of effects that electric interactions may have on particle growth rates. In this set, new particle formation, condensation, ion-aerosol attachment, self-coagulation and scavenging by larger particles were all modeled. The varied parameters were the concentration of charged clusters, the fraction of ion-induced nucleation (the percentage of particles formed charged), and whether condensation onto charged particles 
Table 2. The values of varied parameters used as input in the model in Set 2. The values of new particle formation rate are mean values over the particle formation period.

\begin{tabular}{ll}
\hline Parameter & $\begin{array}{l}\text { Values used as input } \\
\text { in the model }\end{array}$ \\
\hline Concentration of particles in the pre-existing mode & $60 / 200 / 600 / 1200 \mathrm{~cm}^{-3}$ \\
Total new particle formation rate & $1 / 5 / 10 / 50 / 100 \mathrm{~cm}^{-3} \mathrm{~s}^{-1}$ \\
Duration of new particle formation & $1 / 3 / 6 \mathrm{~h}$ \\
Condensational growth rate of neutral particles & $1 / 3 / 10 \mathrm{~nm} \mathrm{~h}^{-1}$ \\
Charged particles and electric interactions included & On/Off \\
\hline
\end{tabular}

Table 3. The values of varied parameters used as input in the model in Set 3.

\begin{tabular}{ll}
\hline Parameter & Values used as input in the model \\
\hline Concentration of charged clusters & $100 / 1000 / 10000 \mathrm{~cm}^{-3}$ \\
Fraction of particles formed negative and positive & $0 \& 0 / 1 \& 1 / 5 \& 5 / 7 \& 3 / 10 \& 0 / 50 \& 50 \%$ \\
Increased condensation onto charged particles & On/Off \\
\hline
\end{tabular}

was enhanced according to Eq. (4) or not. The values of varied parameters are presented in Table 3. In all simulations in Set 3 the average new particle formation rate, duration of new particle formation, condensational growth rate of neutral particles and the concentration of pre-existing particles were $5 \mathrm{~cm}^{-3} \mathrm{~s}^{-1}, 3 \mathrm{~h}, 3 \mathrm{~nm} \mathrm{~h}^{-1}$ and $600 \mathrm{~cm}^{-3}$, respectively.

The concentrations of charged clusters were chosen to include extremely low and high values as compared with atmospheric concentrations (Hirsikko et al., 2011) to provide estimates on the minimum and maximum effects that charged clusters may have on the growth of the nucleation mode. Also for the fraction of ion-induced nucleation, the values are chosen to cover the extreme cases of purely neutral or ion-induced nucleation, as well as a couple of cases closer to those observed in the atmosphere (Manninen et al., 2010). In case there is a sign preference in the onset of ion-induced nucleation (Winkler et al., 2008; Gagné et al., 2010), the formation rates of charged particles may be asymmetrical, a possibility which is also covered in the input parameters.

\subsection{Determining the growth rates}

The total growth rate of the nucleation mode was determined from the simulation results using three different ways:

1. By calculating the growth rate due to condensation, self-coagulation and coagulation scavenging using Eqs. (24), (9) and (13), respectively, and by summing them up to obtain calculated total growth rate $\left(\mathrm{GR}_{\text {calc }}\right)$. In case charged particles are included, Eqs. (8) and (19) are used instead of Eqs. (9) and (13), respectively, when calculating the growth rate due to self-coagulation and coagulation scavenging. If also the condensational flux onto charged particles is increased, then the growth rate due to condensation is calculated using Eq. (25) instead of Eq. (24).

2. By estimating the total growth rate from the increase of count mean diameter of particles smaller than $45 \mathrm{~nm}$ in diameter $\left(\mathrm{GR}_{\mathrm{CMD}}\right)$. The count mean diameter of the nucleation mode is calculated for each moment of time from the simulation data and the value of $\mathrm{GR}_{\mathrm{CMD}}$ is obtained as the time derivative of the count mean diameter. The $45 \mathrm{~nm}$ limit was chosen in order to have minimal amount of pre-existing particles in the range, but also not to lose nucleation mode particles out of the range either.

3. By following the peak concentration of the growing mode $\left(G_{\text {peak }}\right)$. The diameter of the peak of the mode was determined by fitting a second order polynomial to normalized concentration values of five consecutive sections with the highest concentration in the middle. The particle concentrations were normalized using either the linear $\left(d N / d d_{\mathrm{p}}\right)$ or logarithmic $\left(d N / d\left(\log d_{\mathrm{p}}\right)\right)$ width of the sections. The growth rate was then obtained as a slope of a first order polynomial fitted to time and diameter coordinates of the mode peak.

The growth rates $\mathrm{GR}_{\text {calc }}$ and $\mathrm{GR}_{\mathrm{CMD}}$ are not totally independent of each other, since Eqs. (24), (8) and (19) are also based on the change rate of count mean diameter. However, in case $\mathrm{GR}_{\text {calc }}$ and $\mathrm{GR}_{\mathrm{CMD}}$ give similar values, we can be quite confident with our estimates of the growth rates due to different processes. Also, during the new particle formation the value of $\mathrm{GR}_{\mathrm{CMD}}$ cannot be used to estimate the total 

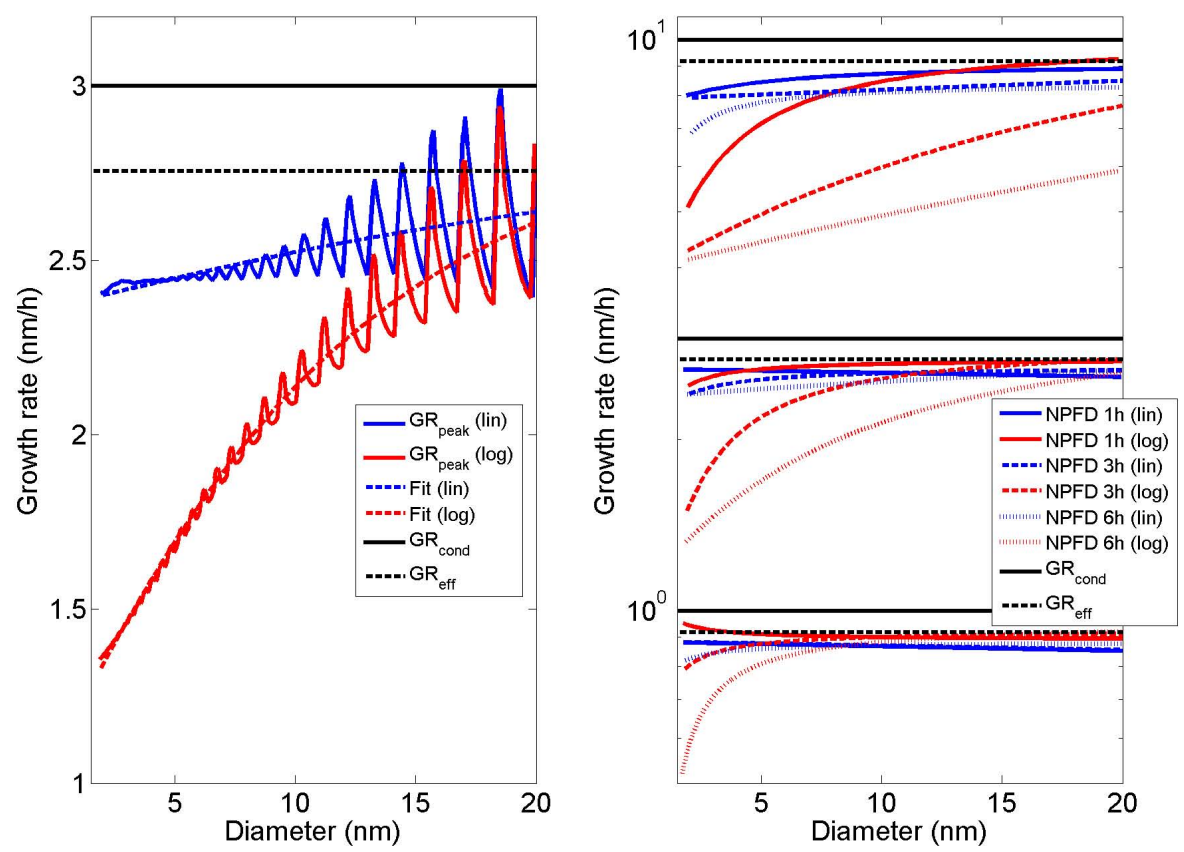

Fig. 1. Left panel: growth rates of an example simulation as a function of diameter. The solid blue (red) line denotes the value of $\mathrm{GR}_{\text {peak }}$ when linear (logarithmic) normalization is used. The blue (red) dashed line denotes an arcus tangent function fitted to values of $\mathrm{GR}_{\mathrm{peak}}$. The black solid and dashed lines denote the values of $\mathrm{GR}_{\text {cond }}$ and $\mathrm{GR}_{\text {eff }}$, respectively. Right panel: arcus tangent functions fitted to values of $\mathrm{GR}_{\text {peak }}$ for simulations with varied input growth rate and duration of new particle formation (NPFD). The blue and red lines denote the used normalization as in left panel with solid, dashed and dotted lines corresponding to particle formation durations of 1,3 and $6 \mathrm{~h}$, respectively. The black solid and dashed lines denote the values of $\mathrm{GR}_{\text {cond }}$ and $\mathrm{GR}_{\mathrm{eff}}$, respectively. The blue and red curves correspond to black lines directly above them.

growth rate, as the freshly formed particles affect the count mean diameter of the mode, but there is no such restriction for the value of $\mathrm{GR}_{\text {calc }}$.

Of these three growth rates, $\mathrm{GR}_{\text {peak }}$ is the most sensitive to the shape of the mode and to changes in that shape. Our approach of using only a few points around the maximum concentration to localize the peak of the mode minimizes the effect of the shape of the mode on the growth rate.

\section{Results and discussion}

\subsection{Numerical issues}

There are four numerical issues related to this work: problems in following the peak of the nucleation mode, normalization of the simulated data, numerical diffusion and error in the increase in the count mean diameter due to the sectional approach. The last two of these issues are important for numerical modeling of new particle formation, whereas the two others are relevant also when analyzing measurement data.

The diameter of the peak of the mode is usually determined by fitting a log-normal function to the particle number size distribution (e.g., Hussein et al., 2004). This method gives relatively good estimates on both the shape of the mode and the diameter of the peak of the mode. However, if the shape of the mode is not close to log-normal, the fit may not be very good. In such cases, the number of data points chosen for the fitting affects the result: more points usually results in a better overall agreement between the data and the fitted function, but the localization of the peak of the mode gets worse.

Our approach of choosing only a few points around the maximum concentration emphasizes the localization of the peak of the mode, but there is a problem in using so few points. In case the peak concentration is found in section $n$, the values of sections from $n-2$ to $n+2$ are used to determine the location of the peak. Now, if the maximum concentration is still in section $n$ at the next moment of time, the same sections are used to determine the location of the peak. In this case, the peak shifts towards bigger sizes, but the shift is somewhat smaller than in case of the maximum concentration being found at the section $n+1$. Thus the difference between consecutive mode peak diameters fluctuates. As a result, the value of $\mathrm{GR}_{\text {peak }}$ determined from these diameters also fluctuates (Fig. 1, left panel). As the fluctuation makes the comparison of results challenging, an arcus tangent function was fitted to the $\mathrm{GR}_{\text {peak }}$ values (Fig. 1, left panel). 
The simulated data describes the particle number size distribution as number concentrations of particles in each size section. Depending on the simulated size range and the number of size sections used, the sections have different widths and thus represent different portions of the distribution. The data have to be normalized in order to have comparable distributions. The usual way to do this is to divide the number concentration of a section with the linear $\left(d N / d d_{p}\right)$ or logarithmic $\left(d N / d\left(\log d_{\mathrm{p}}\right)\right)$ width of the section. These two normalizations are related as follows:

$\frac{d N}{d\left(\log d_{\mathrm{p}}\right)}=\ln 10 \times d_{\mathrm{p}} \frac{d N}{d d_{\mathrm{p}}}$.

As the diameter dependence in Eq. (26) indicates, the normalization affects the shape of the mode and also the diameter of the peak of the mode. Thus, the normalization also affects the value of $\mathrm{GR}_{\text {peak }}$, an example of which is shown in Fig. 1 (left panel). The diameter dependence is introduced to a supposedly constant growth rate, if the logarithmic normalization is used (Fig. 1), an effect which is emphasized when the mode is wide (long period of particle formation and big growth rate of the particles). The usage of a logarithmic normalization also underestimates the growth rate of the mode. In the analysis of simulations in Set 2 and Set 3, only a linear normalization was used.

Numerical diffusion is a well-known problem that usually emerges in numerical models having fixed sections or grids (e.g., Jacobson 2005). In this work, the numerical diffusion was caused mainly by numerical treatment of condensational growth. As described in Sect. 2.2, the particles from one section are divided into two sections after their diameter has increased due to condensation, which results in an artificial broadening of the mode and also changes the shape of the mode. The division of particles into two sections also underestimates the increase in count mean diameter, which was demonstrated in Sect. 2.2.

We are now able to estimate the error in total growth rate caused by both the numerical diffusion and the sectional approach by comparing the values of $\mathrm{GR}_{\text {cond }}, \mathrm{GR}_{\mathrm{eff}}$ and $\mathrm{GR}_{\text {peak }}$. By definition, the difference between the values of $\mathrm{GR}_{\text {cond }}$ and $\mathrm{GR}_{\mathrm{eff}}$ is the error in the count mean diameter due to sectional approach, whereas $\mathrm{GR}_{\text {peak }}$ is also subject to numerical diffusion. The error due to numerical diffusion depends both on the width of the mode and the number of size sections used in the simulation, but the error due to sectional approach depends only on the number of size sections (Fig. 2). In this work, the magnitudes of these two sources of errors are quite similar, the values ranging from a few percent to around 20 percent.

\subsection{Determining the growth rates}

In Sect. 2.4 we described the three methods we use to determine the total growth rate of the mode. The results of these methods for one example simulation are depicted in
Fig. 3. For sizes $>5 \mathrm{~nm}$ in diameter, the values of $\mathrm{GR}_{\text {peak }}$, $\mathrm{GR}_{\mathrm{CMD}}$ and $\mathrm{GR}_{\text {calc }}$ are very similar. The value of $\mathrm{GR}_{\mathrm{CMD}}$ cannot be determined for smaller sizes due to ongoing particle formation: as long as new particles are added to the nucleation mode, the value of $\mathrm{GR}_{\mathrm{CMD}}$ is smaller than the actual modal growth rate as newly formed particles decrease the count mean diameter. The value of $\mathrm{GR}_{\text {peak }}$ cannot be defined in the smallest sizes due to the changes in the shape of the mode. In principle, the fitting of a second order polynomial described in Sect. 2.4 can be done after the peak of the mode is observed, but in practice the shape of the mode changes so rapidly at this stage that the value of $\mathrm{GR}_{\text {peak }}$ overestimates the modal growth rate. The small difference between the value of $\mathrm{GR}_{\text {peak }}$ and the two other modal growth rates in sizes $>5 \mathrm{~nm}$ is mainly due to numerical diffusion.

The value of $\mathrm{GR}_{\text {calc }}$ consists of the growth rates due to condensation $\left(\mathrm{GR}_{\mathrm{eff}}\right)$, self-coagulation $\left(\mathrm{GR}_{\text {scoag }}\right)$ and coagulation scavenging $\left(\mathrm{GR}_{\text {scav }}\right)$ (Fig. 3, left panel). With the value of $\mathrm{GR}_{\text {calc }}$ being quite close to the values of $\mathrm{GR}_{\mathrm{CMD}}$ and $\mathrm{GR}_{\text {peak }}$, we can be quite confident that our methods of estimating the growth rates due to these three processes work reasonably well. Furthermore, as the values of $\mathrm{GR}_{\mathrm{CMD}}$ and $\mathrm{GR}_{\text {calc }}$ are so close to each other, Eqs. (8) and (9) are able to give accurate estimates on the growth rate due to self-coagulation for a nucleation mode covering a substantial range of particle sizes. In the example case depicted in Fig. 3, 57 to $91 \%$ of the total growth was due to condensation, 0 to $10 \%$ was due to self-coagulation and 3 to $41 \%$ was due to coagulation scavenging.

\subsection{Coagulation}

\subsubsection{Self-coagulation}

In order to estimate the growth rate due to self-coagulation, $\mathrm{GR}_{\text {scoag, }}$, using Eqs. (8) and (9), the total particle concentration and the representative diameter has to be specified. The total, neutral, negative and positive concentrations were chosen to be equal to the sum of total, neutral, negative and positive particles in the range 1.5 to $45 \mathrm{~nm}$. For the diameter, the count mean diameter of particles smaller than $45 \mathrm{~nm}$ was used.

The growth rates related to an example simulation of Set 2 are depicted in Fig. 3. In this example case, the duration of new particle formation was $3 \mathrm{~h}$, the mean new particle formation rate was $10 \mathrm{~cm}^{-3} \mathrm{~s}^{-1}$, the input value of $\mathrm{GR}_{\text {cond }}$ was $3 \mathrm{~nm} \mathrm{~h}^{-1}$ and the concentration of background particles was $600 \mathrm{~cm}^{-3}$. In this case, the growth due to self-coagulation is small, but increases with increasing particle diameter, even though the concentration of nucleation mode particles decreases after the center of the mode has grown to around $4 \mathrm{~nm}$ in diameter (Fig. 3, right panel). The value of $\mathrm{GR}_{\text {scoag }}$ is clearly smaller when calculated using Eq. (9) (all particles considered neutral) instead of Eq. (8). 

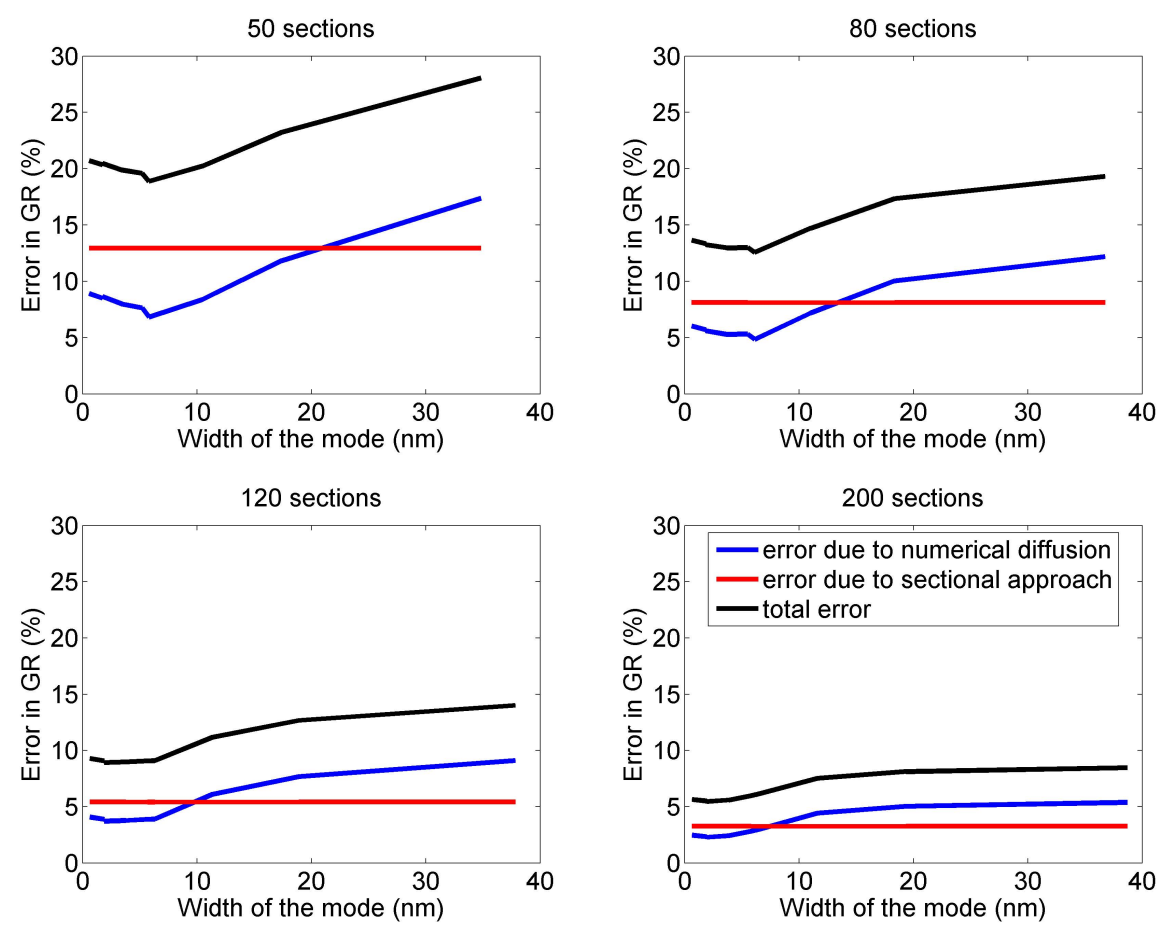

Fig. 2. The error in condensational growth rate as a function of the width of the mode.
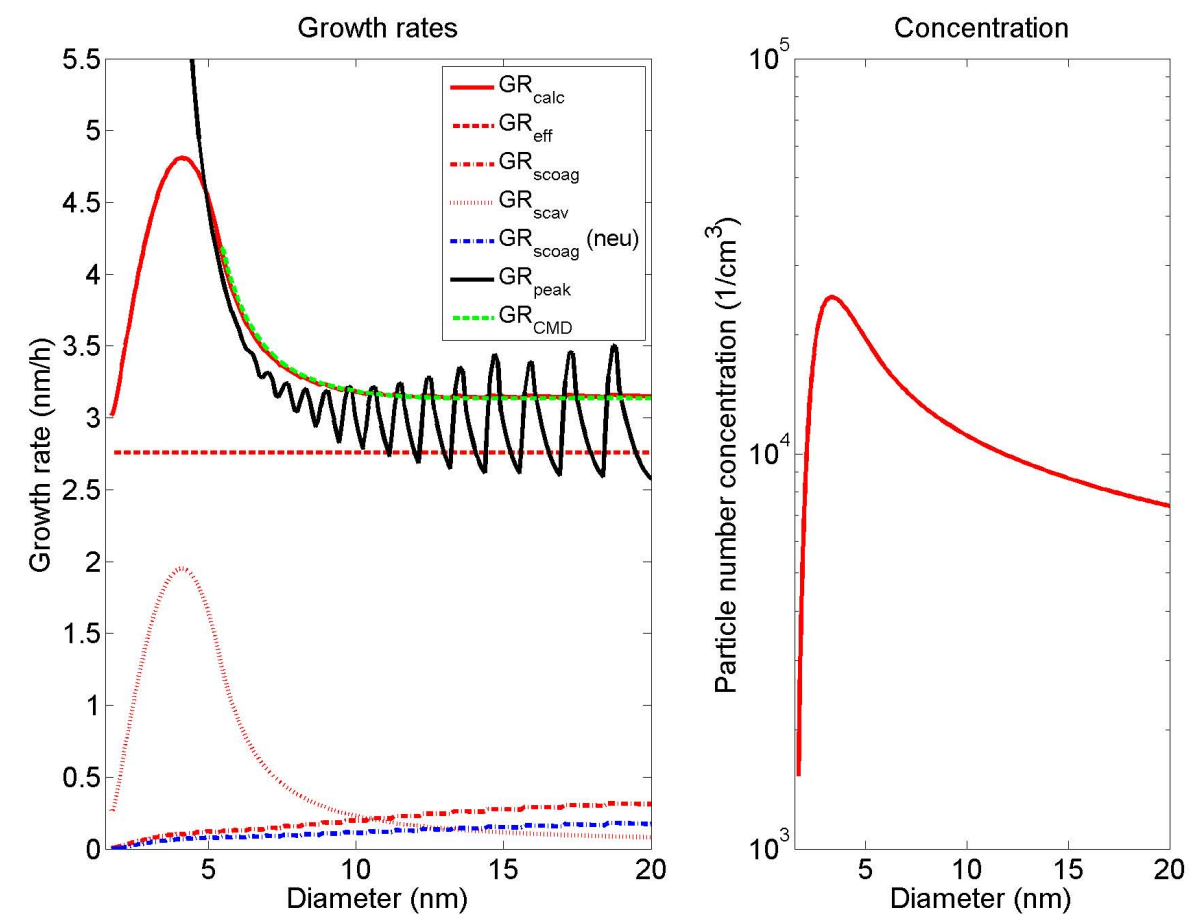

Fig. 3. Left panel: calculated growth rates due to different processes and total growth rates determined using different methods for an example case. The red lines denote the calculated values and the blue line denotes the calculated value without charges taken into account. The solid black and dashed green lines denote the growth rates determined from the mode peak and calculated from the count mean diameter, respectively. Right panel: the concentration of nucleation mode particles as a function of count mean diameter. 


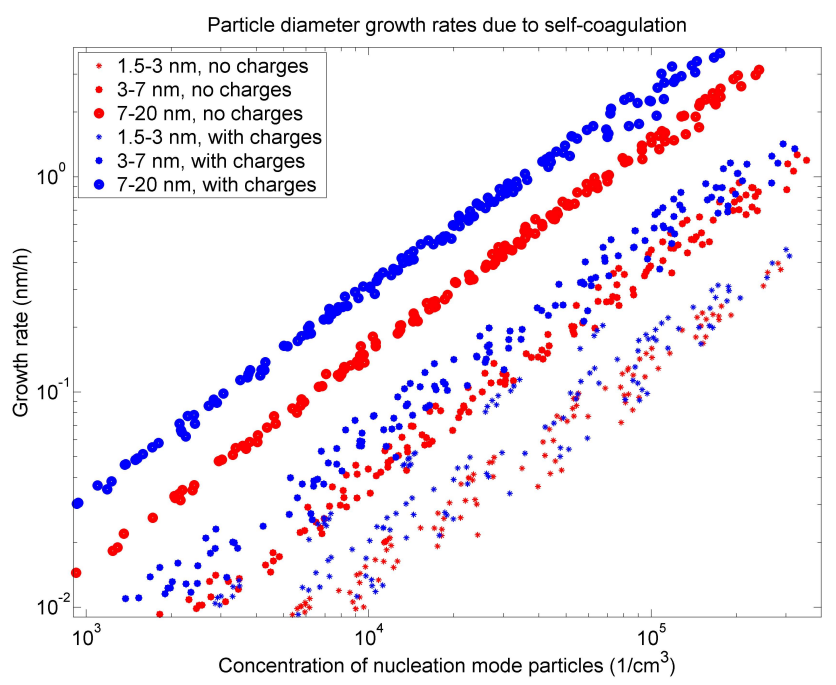

Fig. 4. The growth rates due to self-coagulation from the simulations in Set 2 averaged over size ranges ( 1.5 to 3,3 to 7 and 7 to $20 \mathrm{~nm})$. The red and blue marks denote simulations with or without the charged particles, respectively, and the size of the marker denotes the size range over which the average is taken.

In the results from all simulations in Set 2, the value of $\mathrm{GR}_{\text {scoag }}$ increased approximately linearly with the increasing particle number concentration (Fig. 4). To illustrate the diameter dependence, the mean growth rate due to self-coagulation was calculated for the following three size ranges: 1.5 to $3 \mathrm{~nm}, 3$ to $7 \mathrm{~nm}$ and 7 to $20 \mathrm{~nm}$. The ranges were chosen to match those used in the analysis of measurement data (e.g., Hirsikko et al., 2005; Manninen et al., 2010). There is a clear difference between $\mathrm{GR}_{\text {scoag }}$ calculated for the different size ranges, with bigger particles yielding higher growth rates. When two similarly-sized particles combine to form one bigger particle, the difference between the initial and residual diameters increases with increasing initial diameter, which is demonstrated by the explicit diameter dependence in Eq. (9). This is the main reason for the increase of $\mathrm{GR}_{\text {scoag }}$ with an increasing diameter, though it is further strengthened by the increasing self-coagulation coefficient as a function of diameter in the given size ranges.

The value of $\mathrm{GR}_{\text {scoag }}$ was bigger when the charged particles were included in the simulation. This was due to coagulation coefficients between charged and neutral particles, as well as between oppositely charged particles, being bigger than the corresponding self-coagulation coefficients of neutral particles. For larger particles, the difference between the coagulation coefficients involving a charged particle and those involving only neutral particles gets smaller, but the fraction of charged particles gets bigger. As a result, the difference between the charged and neutral cases prevails also in the bigger sizes.

For a given number of nucleation mode particles, the value of $\mathrm{GR}_{\text {scoag }}$ shows some variability between different simula- tions (Fig. 4). The variability is largest for the smallest size range, and for simulations involving charged particles. Most of the variation is due to averaging over the size ranges: a simulation with a fairly constant concentration of nucleation mode particles (big condensational growth rate and small coagulation sink) and a simulation with rapidly decreasing concentration (small condensational growth rate and big coagulation sink) may give approximately the same average concentration of nucleation mode particles, but the growth rates due to self-coagulation in these two simulations may be different.

\subsubsection{Coagulation scavenging}

In our example case (Fig. 3), a significant part of the growth of the nucleation mode is caused by the apparent growth due to scavenging by larger particles up to sizes of about 5 to $10 \mathrm{~nm}$. In general, the value of $\mathrm{GR}_{\text {scav }}$ increases during the period of the new particle formation due to the changes in width and shape of the nucleation mode. On the other hand, $\mathrm{GR}_{\text {scav }}$ decreases as a function of the particle diameter, as the difference in the relative sizes of the particles in the mode decreases. In our example case, these two properties are in balance at about $4 \mathrm{~nm}$ diameter, whereupon a maximum value of $\mathrm{GR}_{\text {scav }}$ is reached.

The values of $\mathrm{GR}_{\text {scav }}$ from the simulations in Set 2 are depicted in Figure 5 as a function of condensation sink. Here, the condensation sink, rather than coagulation sink, is used to describe the amount of pre-existing larger particles in order to simplify the figure, as the condensation sink has just one value, but the coagulation sink depends on the size of the particles. In order to clarify the condensation sink dependence of the $\mathrm{GR}_{\text {scav }}$, we grouped the results into four categories according to the condensation sink: $<7.3 \times 10^{-4}, 7.3 \times 10^{-4}$ to $2.2 \times 10^{-3}, 2.2 \times 10^{-3}$ to $4.4 \times 10^{-3}$ and $>4.4 \times 10^{-3} \mathrm{~s}^{-1}$. The limits were chosen to match the values of condensation sink of the pre-existing particles in the beginning of the simulation for the three smallest concentrations of the pre-existing particles used in the simulations (Table 2). Most of the simulations with the largest concentration of pre-existing particles were discarded from this part of the analysis for either of the following two reasons: there was no observable event because the particles were scavenged too rapidly, or the growing mode crossed the $45 \mathrm{~nm}$ limit during the determination of the growth rate.

In order to illustrate the diameter dependence of the growth rate due to scavenging, we calculated the mean value of the growth rate for three size ranges: 1.5 to $3 \mathrm{~nm}, 3$ to $7 \mathrm{~nm}$ and 7 to $20 \mathrm{~nm}$. The blue and red marks in the Fig. 5 correspond to the mean values of the growth rate for simulations with or without the charged particles included, respectively. The grey and black lines denote the average values of condensation sink and growth rate due to scavenging for the three size ranges and four condensation sink ranges described above. The value of $\mathrm{GR}_{\text {scav }}$ increases linearly with 


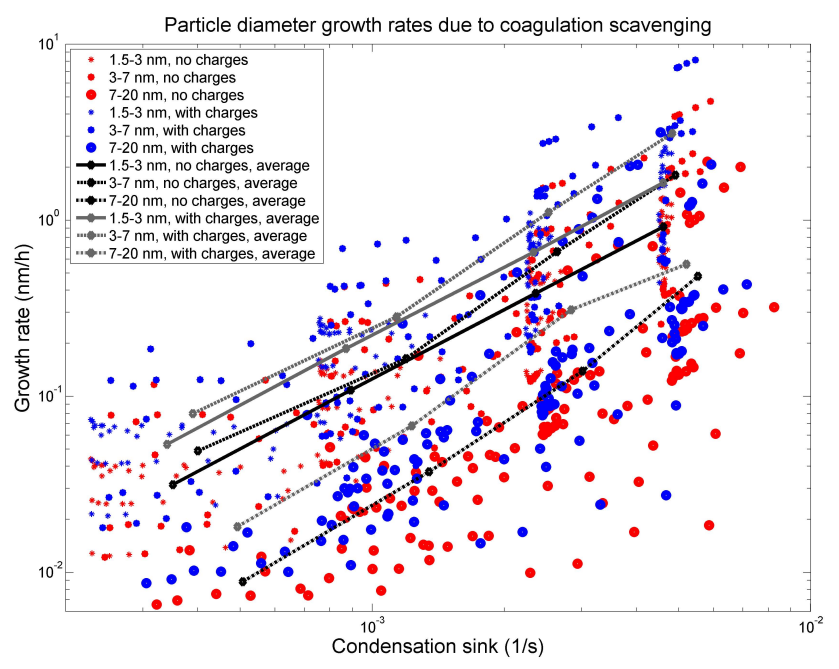

Fig. 5. The growth rates due to coagulation scavenging from the simulations in Set 2 averaged over size ranges (1.5 to 3,3 to 7 and 7 to $20 \mathrm{~nm}$ ). The red and blue marks denote simulations with or without the charged particles, respectively, and the size of the marker denotes the size range over which the average is taken. The points connected with lines denote the average growth rates of simulations with the values of condensation sinks in the ranges $<$ $7.3 \times 10^{-4}, 7.3 \times 10^{-4}$ to $2.2 \times 10^{-3}, 2.2 \times 10^{-3}$ to $4.4 \times 10^{-3}$ and $>4.4 \times 10^{-3} \mathrm{~s}^{-1}$. The grey and black lines correspond to simulations with or without the charged particles, respectively, and solid, dashed and dashed-dotted lines correspond to size ranges 1.5 to 3,3 to 7 and 7 to $20 \mathrm{~nm}$, respectively.

an increasing condensation sink (Fig. 5), which was expected based on Eq. (13). The values of growth rate for a given value of condensation sink vary over an order of magnitude depending on the diameter of the centre of the mode, the width and shape of the growing mode and whether the charged particles are included or not. The inclusion of charged particles increases the value of $\mathrm{GR}_{\text {scav }}$ by a factor of $\sim 1.7$ on average with approximately the same relative increase in each particle size range.

The value of $\mathrm{GR}_{\text {scav }}$ is biggest for the second size range, even though the difference to the first size range is quite small. This behavior is caused by the increase in $\mathrm{GR}_{\text {scav }}$ during the period of new particle formation and the decrease in $\mathrm{GR}_{\text {scav }}$ as a function of diameter, as described earlier in this section.

The diameter dependence and inclusion of charged particles cannot explain all the variation in the values of $\mathrm{GR}_{\text {scav }}$ as a function of condensation sink. The rest of the variation is due to varying shapes and widths of the growing modes as well as the averaging over the diameter ranges.

\subsubsection{Semi-apparent growth due to self-coagulation}

In self-coagulation, the particle concentration in the mode decreases, but the average diameter increases, and thus the mode grows in size. If the mode is wide enough, the relative difference in the volumes of the particles in the mode may be several orders of magnitude. As a result, the coagulation between the smallest and biggest particles is essentially a sink for the smaller ones. Such coagulation increases the count mean diameter of the mode and also shifts the peak concentration of the mode to bigger sizes, though the real increase in the diameter of the bigger particles is very small. This kind of growth may be described as semi-apparent.

A significant amount of semi-apparent growth was observed in simulations with wide nucleation modes and high particle number concentrations. The semi-apparent growth rate decreases as a function of particle diameter, as the relative difference in the particle sizes within the mode decreases. The ongoing particle formation increases the semiapparent growth rate as the nucleation mode gets wider. In the simulations where semi-apparent growth was observed, the concentration of nucleation mode particles was $>1 \times 10^{4} \mathrm{~cm}^{-3}$. The concentration needed in order to have significant amount of semi-apparent growth is very much dependent on the width and shape of the mode. For example, in the simulations with the nucleation mode narrower than $10 \mathrm{~nm}$ and significant amount of semi-apparent growth, the concentration of nucleation mode particles was $>8 \times 10^{4} \mathrm{~cm}^{-3}$.

\subsection{Charges}

In the previous section we showed that charged particles increase the values of $\mathrm{GR}_{\text {scoag }}$ and $\mathrm{GR}_{\text {scav }}$ because of the bigger coagulation rates. The magnitude of this effect depends on the number concentration of charged particles in the nucleation mode and pre-existing background aerosol. The fraction of charged particles in the smallest sizes is dominated by the fraction of particles being formed charged (ion-induced nucleation). When the particles grow to larger sizes, the fraction of charged particles is affected by two processes: neutralization of charged particles through ion-ion recombination and charging of neutral particles through ion-aerosol attachment. Eventually, the fraction of charged particles in the mode approaches the charge equilibrium. The time it takes to reach the charge equilibrium depends mainly on the total growth rate of the nucleation mode and the concentration of charged clusters (Kerminen et al., 2007). The bigger the growth rate and the smaller the concentration of charged clusters, the longer it takes to reach the charge equilibrium and the bigger the particles have grown by that time. If the initial fraction of charged particles is higher than predicted by the charge equilibrium, the fraction of charged particles decreases to a value below the charge equilibrium and then starts to approach the equilibrium value. This behavior results from the increasing fraction of charged particles in the charge equilibrium as a function of particle diameter.

Let us consider a situation, in which new particles are formed and then grow to bigger sizes by condensation. Let 

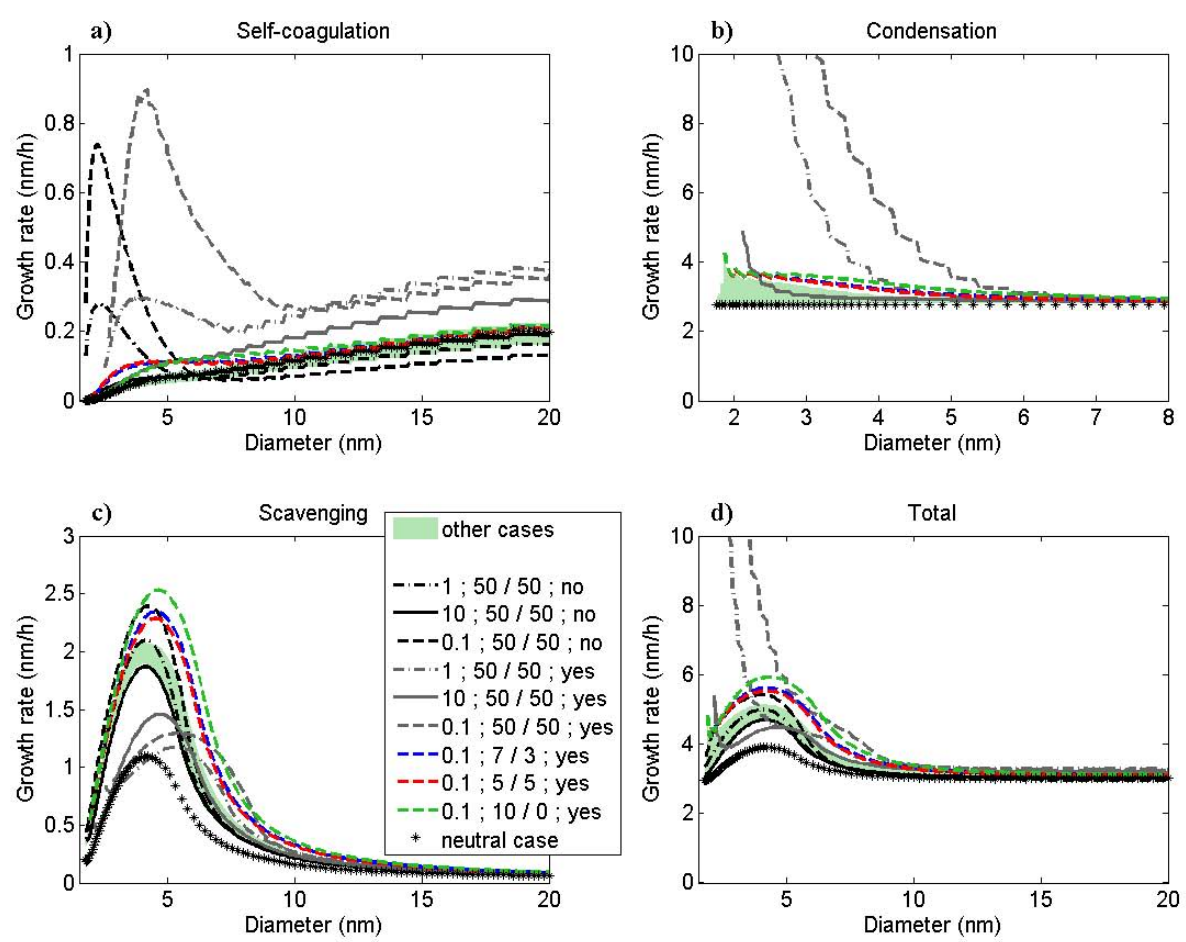

Fig. 6. Calculated values of the total growth rate and growth rate due to different processes. In the legend, the first number denotes the concentration of charged sub $1.5 \mathrm{~nm}$ clusters in $10^{3} \mathrm{~cm}^{-3}$, the second and the third number denote the percent of particles formed negatively charged and positively charged, respectively, and the last mark denotes whether the condensation onto charged particles was enhanced (yes) or not (no). The green area covers the values of growth rates from other simulations in Set 3 and the black stars denote a purely neutral simulation with otherwise the same input parameters.

us assume further that some of the particles are formed as charged and the nucleation mode is subject to selfcoagulation, coagulation scavenging and ion-aerosol attachment. In this scenario, the total growth rate of the mode depends on the fraction of charged particles in the mode via both of the above-mentioned coagulation processes and also via condensation, if polar molecules are let to condense more rapidly on charged particles.

The fraction of charged particles in the smallest sizes depends mostly on the fraction of particles formed as charged. When the fraction of ion-induced nucleation is increased, the growth rate due to self-coagulation is increased in the smallest sizes (Fig. 6a). If the concentration of charged clusters is increased, the fraction of charged particles approaches the value in charge equilibrium more rapidly. This is important for the growth rate due to self-coagulation only if the fraction of ion-induced nucleation is high ( $\geq 10 \%)$, in which case the increase in concentration of charged clusters decreases the growth rate due to self-coagulation (Fig. 6a).

When the enhanced condensation flux onto charged particles due to electric interactions is taken into account, the condensational growth rate of the total nucleation mode increases (Fig. 6b). If the fraction of ion-induced nucleation is increased, the total condensational growth rate increases due to bigger fraction of charged particles in the smallest sizes. With a bigger condensational growth rate, the fraction of charged particles approaches the value in charge equilibrium more slowly, which is a positive feedback for the increase in condensational growth rate. Increasing the number of charged clusters has an opposite effect: the fraction of charged particles approaches the value in charge equilibrium more rapidly, which results in a smaller condensational growth rate (Fig. 6b).

The increase in the total condensational growth rate due to increased condensation flux onto charged particles increases the growth rate due to self-coagulation via two effects. First of all, the total particle number concentration stays higher due to bigger condensational growth rate, as the coagulation processes have less time to remove the particles. Secondly, the fraction of charged particles stays higher, as described above (Fig. 6a).

The coagulation rate between a nucleation mode particle and any background particle is increased when either of these two particles is charged, as compared to a case when both particles are neutral. Thus, the apparent growth rate due to coagulation scavenging is increased, if charged particles are included in a simulation (Fig. 6c). The fraction of charged particles in the nucleation mode usually plays a minor role 
in this process, as the coagulation sink of neutral particles in the nucleation mode is also increased due to the charged background particles.

A more complicated issue is the shape of the nucleation mode: the broader the nucleation mode the bigger the growth rate due to coagulation scavenging. If the fraction of charged particles is high and the condensation flux onto charged particles increases, the total condensational growth rate increases. The increase in the total growth rate is diameter dependent, since both the fraction of charged particles and the increase in condensation flux decrease as a function of particle diameter. Due to the increased condensational growth in the small sizes, the count mean diameter of the nucleation mode increases rapidly. Now, as the condensational growth rate decreases as a function of diameter, the smaller end of the mode grows more rapidly than the bigger end of the mode. As a net result, the nucleation mode grows more rapidly but stays narrower. This phenomenon is illustrated in Fig. 7, where the total particle number size distribution is depicted for a simulation with only neutral particles (neutral case) and a corresponding simulation with purely ion-induced nucleation and increased condensation onto charged particles (charged case). As a result, the growth rate due to coagulation scavenging is smaller in simulations with pure ion-induced nucleation and increased condensation onto charged particles than in other simulations with charged particles included (Fig. 6c).

\section{Implications to growth rate analysis}

The modal growth rate determined from the measured data has frequently been used to estimate the concentration of condensable vapors (e.g., Kulmala et al., 2001; Kristensson et al., 2008) as well as their source rates (Kulmala et al., 2005). In such analyses, only the growth rate due to condensation should be used to determine the vapor concentrations. However, the growth rate determined from the time evolution of the center of the mode is also subject to other processes, e.g. coagulation. If a regional new particle formation event has been observed in the measured evolution of total particle size distribution, the modal growth rate is often determined by fitting a line to the time and diameter coordinates of the mode peak. The coordinates can be determined using either of the following methods:

Method 1: a log-normal mode is fitted to the particle number size distribution at each moment of time to determine the diameter of the peak of the mode (Hussein et al., 2005; Dal Maso et al., 2005).

Method 2: a normal distribution is fitted to the measured concentrations of each size section/channel to determine the moment of time of the maximum concentration in that size (Lehtinen and Kulmala 2003; Hirsikko et al., 2005).

If Method 1 has been used to determine the modal growth rate, the growth rate due to self-coagulation and coagulation scavenging should be subtracted from the modal growth rate to get the growth rate due to condensation. In order to determine the growth rate due to self-coagulation, the nucleation mode has to be defined. The growth rate due to selfcoagulation can then be estimated using Eq. (9). For the growth rate due to coagulation scavenging, the coagulation sinks of the differently sized particles in the nucleation mode have to be determined, after which the growth rate due to coagulation scavenging can be estimated using Eq. (13).

If Method (2) has been used and the coagulation sink stays approximately constant during the new particle formation event, only the growth rate due to self-coagulation needs to be subtracted from the modal growth rate in order to get the growth rate due to condensation. The concentration of particles in a given size section/channel at a given moment of time decreases due to coagulation scavenging, but the relative decrease in the concentration stays constant as a function of time when the coagulation sink stays constant. Thus, the moment of maximum concentration in a given size section/channel does not change due to coagulation scavenging. The growth rate due to self-coagulation still has to be taken into account, which can be done the same way as with the Method 1.

If the data are taken from an aerosol dynamical model with fixed sections, the growth rate due to condensation obtained with the two methods described above is the effective condensational growth rate. In order to determine the vapor concentrations, the real condensational growth rate is needed. The difference between these two values of condensational growth rate is caused by the numerical diffusion and the division of particles into sections when condensation is simulated. The error due to numerical diffusion is very case dependent, as demonstrated in Fig. 2. If the sections in the model are equally divided on a logarithmic axis, the error due to division of particles can be estimated using Eq. (24). In aerosol dynamical simulations, the concentrations of condensing vapors are usually known. Thus the difference between the real and the effective condensational growth rate can be used to estimate the error in the condensational growth rate due to numerical diffusion and the division of particles into sections, when known concentrations of condensing vapors are used. This underestimation can easily be of the order of $20 \%$, but at least a part of this error can be taken into account using Eq. (24) to calculate the effective growth rate.

\section{Summary and conclusions}

The processes governing the growth of a nucleation mode are condensation, self-coagulation and coagulation scavenging. The growth due to coagulation scavenging is only apparent, as the particles in the mode do not get bigger. The growth due to self-coagulation may be partly semi-apparent, in the case of sufficiently high concentration of nucleation mode particles and wide enough nucleation mode. In semiapparent growth, the mode grows mainly due to removal of 


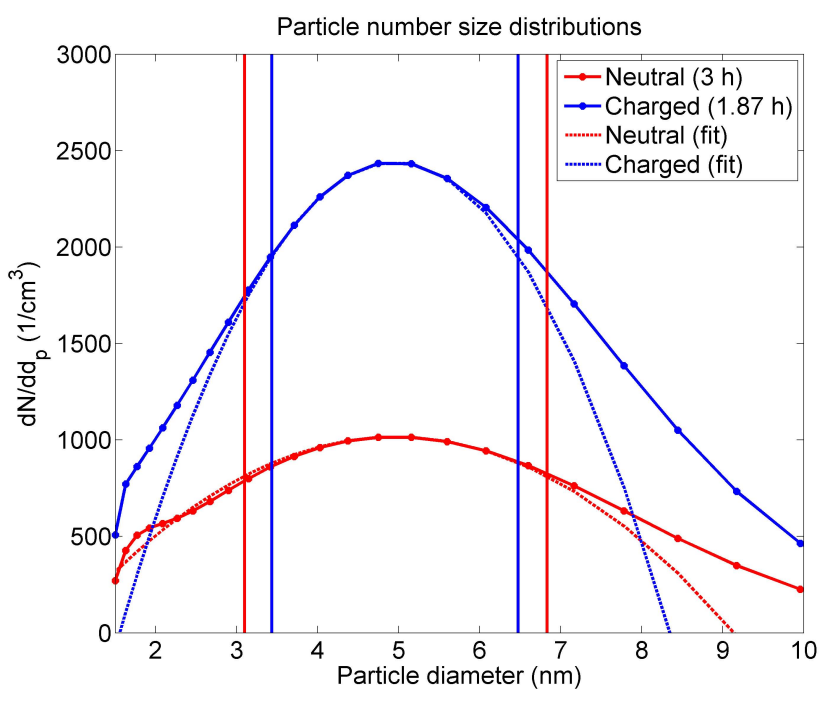

Fig. 7. Two example particle number size distributions. The blue (red) line denotes a simulation with (without) charged particles and enhanced condensation onto charged particles included. The vertical lines denote the diameters corresponding to concentrations $20 \%$ less than the top concentration of the distribution. The dashed lines (fit) denote the second order polynomials fitted to five consecutive points around the peaks of the distributions.

particles in the mode with very little real growth of the particles. Charged particles may affect the growth rate due to these processes by increasing the condensational flux of polar molecules onto charged particles, and by coagulation rate between a charged and a neutral particle being bigger than the corresponding coagulation rate of two neutral particles.

The method of fixed size sections used in simulating the condensational growth of the particles was found to underestimate the condensational growth rate of the mode as the division of the particles into the sections underestimates the count mean diameter of the mode. The error in the value of condensational growth rate in this study was 3 to $13 \%$, depending on the number of size sections used. This error can be taken into account with a simple equation derived in this paper. Numerical diffusion was found to decrease the observed condensational growth rate of a nucleation mode with a value depending on the width and shape of the mode. The error in the value of condensational growth rate in this study was 2 to $18 \%$.

We provided analytical formulae to estimate the growth rate of a nucleation mode due to self-coagulation and the apparent growth rate due to scavenging by larger particles. These formulae were used on a set of simulations covering a wide range of atmospheric conditions. The modal growth rates were determined from the simulation results by summing the contribution of each process, by calculating the increase rate in the count mean diameter of the mode and by following the peak concentration of the mode. The results of these three methods were compared with each other and the means used to estimate the growth rate due to selfcoagulation and coagulation scavenging were found to work quite well. We also demonstrated that the $d N / d d_{p}$ normalization should be used, instead of the $d N / d\left(\log d_{\mathrm{p}}\right)$ normalization, when determining the growth rate from the time evolution of the peak concentration.

We investigated the role of charged particles and electric interactions in the growth of a nucleation mode. Charged particles were found to increase significantly the growth rate due to both self-coagulation and coagulation scavenging. The growth rate due to self-coagulation was increased on average by a factor of $\sim 2$ when the count mean diameter of the mode was in the range of 7 to $20 \mathrm{~nm}$ and by a factor of $\sim 1.5$ when the count mean diameter was $<7 \mathrm{~nm}$. The growth rate due to coagulation scavenging was increased by a factor of $\sim 1.7$ on average.

In case of increased condensation onto charged particles, the total condensational growth rate of a nucleation mode may increase significantly in the very early steps of the growth. With $10 \%$ of particles formed charged and concentration of charged sub $1.5 \mathrm{~nm}$ clusters set to $1000 \mathrm{~cm}^{-3}$, the condensational growth rate of the mode was increased by around $35 \%$, when the count mean diameter was smaller than $\sim 3 \mathrm{~nm}$. This effect is even bigger, if more particles are formed charged, or if the concentration of the charged clusters is smaller, as the charge equilibrium is reached more slowly.

The analytical formulae provided by this paper were designed to provide the growth rates due to different processes from aerosol dynamic simulations, but the same principles can be used to determine the growth rates from measurement data. The approach of describing the mode using the count mean diameter instead of the center of the mode might be useful when analyzing the growth rate of the mode in the very early stages, where the mode has not yet achieved the lognormal shape.

Acknowledgements. Tuomo Nieminen is acknowledged for valuable discussion and providing support data. This work has been supported by European Commission 6th Framework program project EUCAARI, contract no. 036833-2 (EUCAARI), and by Academy of Finland project ComQuaCC: Computational research chain from quantun chemistry to climate change, project no. 135199. The support by the Academy of Finland Centre of Excellence program (project no. 211483, 211484 and 1118615) is also gratefully acknowledged.

Edited by: A. Wiedensohler

\section{References}

Birmili, W., Berresheim, H., Plass-Dülmer, C., Elste, T., Gilge, S., Wiedensohler, A., and Uhrner, U.: The Hohenpeissenberg aerosol formation experiment (HAFEX): a longterm study including size-resolved aerosol, $\mathrm{H}_{2} \mathrm{SO}_{4}, \mathrm{OH}$, and 
monoterpenes measurements, Atmos. Chem. Phys., 3, 361-376, doi:10.5194/acp-3-361-2003, 2003.

Dal Maso, M., Kulmala, M., Riipinen, I., Wagner, R., Hussein, T., Aalto, P. P., and Lehtinen, K. E. J.: Formation and growth of fresh atmospheric aerosols: eight years of aerosol size distribution data from SMEAR II, Hyytiälä, Finland, Boreal Env. Res., 10, 323336, 2005.

Dal Maso, M., Sogacheva, L., Aalto, P. P., Riipinen, I., Komppula, M., Tunved, P., Korhonen, L., Suur-Uski, V., Hirsikko, A., Kurtén, T., Kerminen, V.-M., Lihavainen, H., Viisanen, Y., Hansson, H. C., and Kulmala, M.: Aerosol size distribution measurements at four Nordic field stations: identification, analysis and trajectory analysis of new particle formation bursts, Tellus, 59B, 350-361, 2007.

Fuchs, N.: The Mechanics of Aerosols, Dover, Mineola, N.Y., USA, 408 pp., 1964.

Fuchs, N. A. and Sutugin, A. G.: Highly dispersed aerosols, in: Topics in current aerosol research, edited by: Hidy G. M. and Brock J. R., Pergamon Press, 1-60, 1971.

Gagné, S., Laakso, L., Petäjä, T., Kerminen, V.-M., and Kulmala, M.: Analysis of one year of Ion-DMPS data from the SMEAR II station, Finland, Tellus, 60B, 318-329, 2008.

Gagné, S., Nieminen, T., Kurtén, T., Manninen, H. E., Petäjä, T., Laakso, L., Kerminen, V.-M., Boy, M., and Kulmala, M.: Factors influencing the contribution of ion-induced nucleation in a boreal forest, Finland, Atmos. Chem. Phys., 10, 3743-3757, doi:10.5194/acp-10-3743-2010, 2010.

Gong, Y., Hu, M., Cheng, Y., Su, H., Yue, D., Liu, F., Wiedensohler, A., Wang, Z., Kalesse, H., Liu, S., Wu, Z., Xiao, K., Mi, P., and Zhang, Y.: Competition of coagulation sink and source rate: New particle formation in the Pearl River Delta of China, Atmos. Environ., 44, 3278-3285, 2010.

Held, A., Nowak, A., Birmili, W., Wiedensohler, A., Forkel, R., and Klemm, O.: Observations of particle formation and growth in a mountainous forest region in central Europe, J. Geophys. Res., 109, D23204, doi:10.1029/2004JD005346, 2004.

Hirsikko, A., Laakso, L., Hõrrak, U., Aalto, P. P., Kerminen, V.M., and Kulmala, M.: Annual and size dependent variation of growth rates and ion concentrations in boreal forest, Boreal Env. Res., 10, 357-369, 2005.

Hirsikko, A., Nieminen, T., Gagné, S., Lehtipalo, K., Manninen, H. E., Ehn, M., Hõrrak, U., Kerminen, V.-M., Laakso, L., McMurry, P. H., Mirme, A., Mirme, S., Petäjä, T., Tammet, H., Vakkari, V., Vana, M., and Kulmala, M.: Atmospheric ions and nucleation: a review of observations, Atmos. Chem. Phys., 11, 767798, doi:10.5194/acp-11-767-2011, 2011.

Hoppel, W. A. and Frick, G. M.: Ion-aerosol attachment coefficients and the steady-state charge distribution on aerosol in a bipolar environment, Aerosol Sci. Technol., 5, 1-21, 1986.

Hõrrak, U., Aalto, P. P., Salm, J., Komsaare, K., Tammet, H., Mäkelä, J. M., Laakso, L., and Kulmala, M.: Variation and balance of positive air ion concentrations in a boreal forest, Atmos. Chem. Phys., 8, 655-675, doi:10.5194/acp-8-655-2008, 2008.

Howard, J., Wersborg, B., and Williams, G.: Coagulation of carbon particles in premixed flames, Faraday Symp. Chem. Soc., 7, 109119, 1973.

Hussein, T., Puustinen, A., Aalto, P. P., Mäkelä, J. M., Hämeri, K., and Kulmala, M.: Urban aerosol number size distributions, Atmos. Chem. Phys., 4, 391-411, doi:10.5194/acp-4-391-2004,
2004.

Iida, K., Stolzenburg, M. R., McMurry, P. H., and Smith, J. N.: Estimating nanoparticle growth rates from sizedependent charged fractions: Analysis of new particle formation events in Mexico City, J. Geophys. Res., 113, D05207, doi:10.1029/2007JD009260, 2008.

Jacobson, M. Z.: Fundamentals of Atmospheric Modeling, Cambridge University Press, 2005.

Kerminen, V.-M., Pirjola, L., and Kulmala, M.: How significantly does coagulational scavenging limit atmospheric particle production?, J. Geophys. Res., 106, 24119-24126, 2001.

Kerminen, V.-M., Lehtinen, K. E. J., Anttila, T., and Kulmala, M.: Dynamics of atmospheric nucleation mode particles: a timescale analysis, Tellus, 56B, 135-146, 2004.

Kerminen, V.-M., Anttila, T., Petäjä, T., Laakso, L., Gagné, S., Lehtinen, K. E. J., and Kulmala, M.: Charging state of the atmospheric nucleation mode: Implications for separating neutral and ion-induced nucleation, J. Geophys. Res., 112, D21205, doi:10.1029/2007JD008649, 2007.

Kristensson, A., Dal Maso, M., Swietlicki, E., Hussein, T., Zhou, J., Kerminen, V.-M., and Kulmala, M.: Characterization of new particle formation events at a background site in Southern Sweden: relation to air mass history, Tellus, 60B, 330-344, 2008.

Kuang, C., McMurry, P. H., and McCormick, A. V.: Determination of cloud condensation nuclei production from measure new particle formation events, Geophys. Res. Lett., 36, L09822, doi:10.1029/2009GL037584, 2009.

Kulmala, M., Pirjola, L., and Mäkelä, J. M.: Stable sulphate clusters as a source of new atmospheric particles, Nature, 404, 66-69, 2000.

Kulmala, M., Dal Maso, M., Mäkelä, J. M., Pirjola, L., Väkevä, M., Aalto, P., Miikkulainen, P., Hämeri, K., and O'Dowd, C. D.: On the formation, growth and composition of nucleation mode particles, Tellus, 53B, 479-490, 2001.

Kulmala, M., Laakso, L., Lehtinen, K. E. J., Riipinen, I., Dal Maso, M., Anttila, T., Kerminen, V.-M., Hõrrak, U., Vana, M., and Tammet, H.: Initial steps of aerosol growth, Atmos. Chem. Phys., 4, 2553-2560, doi:10.5194/acp-4-2553-2004, 2004.

Kulmala, M., Petäjä, T., Mönkkönen, P., Koponen, I. K., Dal Maso, M., Aalto, P. P., Lehtinen, K. E. J., and Kerminen, V.-M.: On the growth of nucleation mode particles: source rates of condensable vapor in polluted and clean environments, Atmos. Chem. Phys., 5, 409-416, 2005, http://www.atmos-chem-phys.net/5/409/2005/.

Kulmala, M., Riipinen, I., Sipilä, M., Manninen, H. E., Petäjä, T., Junninen, H., Dal Maso, M., Mordas, G., Mirme, A., Vana, M., Hirsikko, A., Laakso, L., Harrison, R. M., Hanson, I., Leung, C., Lehtinen, K. E. J., and Kerminen, V.-M.: Towards direct measurement of atmospheric nucleation, Science 318, 89-92, 2007.

Kulmala, M. and Kerminen, V.-M.: On the formation and growth of atmospheric nanoparticles, Atmos. Res., 90, 132-150, 2008.

Laakso, L., Kulmala, M., and Lehtinen, K. E. J.: Effect of condensation rate enhancement factor on 3-nm (diameter) particle formation in binary ion-induced and homogeneous nucleation, J. Geophys. Res., 108, 4574, doi:10.1029/2003JD003432, 2003.

Laakso, L., Gagné, S., Petäjä, T., Hirsikko, A., Aalto, P. P., Kulmala, M., and Kerminen, V.-M.: Detecting charging state of ultra-fine particles: instrumental development and ambient measurements, Atmos. Chem. Phys., 7, 1333-1345, 
doi:10.5194/acp-7-1333-2007, 2007.

Lehtinen, K. E. J. and Zachariah, M. R.: Self-preserving Theory for the Volume Distribution of Particles Undergoing Brownian Coagulation, J. Colloid Interf. Sci., 242, 314-318, 2001.

Lehtinen, K. E. J. and Kulmala, M.: A model for particle formation and growth in the atmosphere with molecular resolution in size, Atmos. Chem. Phys., 3, 251-257, doi:10.5194/acp-3-251-2003, 2003.

Lehtinen, K. E. J., Dal Maso, M., Kulmala, M., and Kerminen, V.M.: Estimating nucleation rates from apparent particle formation rates and vice versa: Revised formulation of the KerminenKulmala equation, J. Aerosol Sci., 38, 988-994, 2007.

Leppä, J., Kerminen, V.-M., Laakso, L., Korhonen, H., Lehtinen, K. E. J., Gagné, S., Manninen, H. E., Nieminen, T., and Kulmala, M.: Ion-UHMA: a model for simulating the dynamics of neutral and charged aerosol particles, Boreal Env. Res., 14, 559-575, 2009.

Lushnikov, A. A. and Kulmala, M.: Charging of aerosol particles in the near free-molecule regime, Eur. Phys. J., D29, 345-355, 2004.

Manninen, H. E., Nieminen, T., Asmi, E., Gagné, S., Häkkinen, S. K., Lehtipalo, K., Aalto, P., Vana, M., Mirme, A, Mirme, S., Hõrrak, U., Plass-Dülmer, C., Stange, G., Kiss, G., Hoffer, A., Tör, N., Moerman, M., Henzing, B., de Leeuw, G., Brinkenberg, M., Kouvarakis, G. N., Bougiatioti, A., Mihalopoulos, N., O'Dowd, C., Ceburnis, D., Arneth, A., Svenningsson, B., Swietlicki, E., Tarozzi, L., Decesari, S., Facchini, M. C., Birmili, W., Sonntag, A., Wiedensohler, A., Boulon, J., Sellegri, K., Laj, P., Gysel, M., Bukowiecki, N., Weingartner, E., Wehrle, G., Laaksonen, A., Hamed, A., Joutsensaari, J., Petäjä, T., Kerminen, V.-M., and Kulmala, M.: EUCAARI ion spectrometer measurements at 12 European sites - analysis of new particle formation events, Atmos. Chem. Phys., 10, 7907-7927, doi:10.5194/acp-10-79072010, 2010.

Merikanto, J., Spracklen, D. V., Mann, G. W., Pickering, S. J., and Carslaw, K. S.: Impact of nucleation on global CCN. Atmos. Chem. Phys., 9, 8601-8616, 2009, http://www.atmos-chem-phys.net/9/8601/2009/.

Mick, H. J., Hospital, A., and Roth, P.: Computer simulation of sooth particle coagulation in low pressure flames, J. Aerosol Sci., 22, 8319-841, 1991.

Nadykto, A. B. and Yu, F.: Uptake of neutral polar vapor molecules by charged clusters/particles: Enhancement due to dipole-charge interaction, J. Geophys. Res., 108, 4717, doi:10.1029/2003JD003664, 2003.

Nieminen, T., Lehtinen, K. E. J., and Kulmala, M.: Sub-10 nm particle growth by vapor condensation - effects of vapor molecule size and particle thermal speed, Atmos. Chem. Phys., 10, 97739779, doi:10.5194/acp-10-9773-2010, 2010.
Pierce, J. R. and Adams, P. J.: Efficiency of cloud condensation nuclei formation from ultrafine particles, Atmos. Chem. Phys., 7, 1367-1379, doi:10.5194/acp-7-1367-2007, 2007.

Pierce, J. R. and Adams, P. J.: Uncertainty in global CCN concentrations from uncertain aerosol nucleation and primary emission rates, Atmos. Chem. Phys., 9, 1339-1356, doi:10.5194/acp-91339-2009, 2009.

Seinfeld, J. H. and Pandis, S. N.: Atmospheric Chemistry and Physics: From air pollution to climate change, John Wiley \& Sons, 2006.

Spracklen, D. V., Carslaw, K. S., Kulmala, M., Kerminen, V.-M., Mann, G. W., and Sihto, S.-L.: The contribution of boundary layer nucleation events to total particle concentrations on regional and global scales, Atmos. Chem. Phys., 6, 5631-5648, doi:10.5194/acp-6-5631-2006, 2006.

Spracklen, D. V., Carslaw, K. S., Kulmala, M., Kerminen, V.-M., Sihto, S.-L., Riipinen, I., Merikanto, J., Mann, G. W., Chipperfield, M. P., Wiedensohler, A., Birmili, W., Lihavainen, H.: Contribution of particle formation to global cloud condensation nuclei concentrations, Geophys. Res. Lett., 35, L06808, doi:10.1029/2007GL033038, 2008.

Stolzenburg, M. R., McMurry, P. H., Sakurai, H., Smith, J. N., Mauldin III, R. L., Eisele, F. L., and Clement, C. F.: Growth rates of freshly nucleated atmospheric particles in Atlanta, J. Geophys. Res., 110, D22S05, doi:10.1029/2005JD005935, 2005.

Verheggen, B. and Mozurkewich, M.: An inverse modeling procedure to determine particle growth and nucleation rates from measured aerosol size distributions, Atmos. Chem. Phys., 6, 29272942, doi:10.5194/acp-6-2927-2006, 2006.

Wang, L., Khalizov, A. F., Zheng, J., Xu, W., Ma, Y., Lal, V., and Zhang, R.: Atmospheric nanoparticles formed from heterogeneous reactions of organics, Nat. Geosci., 3, 238-242, doi:10.1038/ngeo778, 2010.

Winkler, P. M., Steiner, G., Virtala, A., Vehkamäki, H., Noppel, M., Lehtinen, K. E. J., Reischl, G. P., Wagner, P. E., and Kulmala, M.: Heterogeneous Nucleation Experiments Bridging the Scale from Molecular Ion Clusters to Nanoparticles, Science, 319, 1374, doi:10.1126/science. 1149034, 2008.

Yu, F., Luo, G., Bates, T. S., Anderson, B., Clarke, A., Kapustin, V., Yantosca, R. M., Wang, Y., and Wu, S.: Spatial distributions of particle number concentrations in the global troposphere: Simulations, observations, and implications for nucleation mechanisms, J. Geophys. Res., 115, D17205, doi:10.1029/2009JD013473, 2010. 